\title{
Chemo-enzymatic synthesis and in vitro cytokine profiling of tailor-made oligofructosides
}

\author{
Arne Homann ${ }^{1,2}$, Malte Timm ${ }^{1}$ and Jürgen Seibel ${ }^{1 *}$
}

\begin{abstract}
Background: It is well known that carbohydrates play fundamental roles in cell signaling and infection processes as well as tumor formation and progression. However, the interaction pathways and cellular receptors targeted by carbohydrates and glycoconjugates remain poorly examined and understood. This lack of research stems, at least to a major part, from accessibility problems of large, branched oligosaccharides.

Results: To test glycan - cell interactions in vitro, a variety of tailored oligosaccharides was synthesized chemo-enzymatically. Glycosyltransferases from the GRAS organisms Bacillus megaterium (SacB) and Aspergillus niger (Suc1) were used in this study. Substrate engineering of these glycosyltransferases generally acting on sucrose leads to the controlled formation of novel tailored di-, tri- and tetrasaccharides. Already industrially used as prebiotics in functional food, the immunogenic potential of novel oligosaccharides was characterized in this study. A differential secretion of CXCL8 and CCL2 was observed upon oligosaccharide co-cultivation with colorectal epithelial Caco-2 cells.
\end{abstract}

Conclusion: Pure carbohydrates are able to stimulate a cytokine response in human endothelial cells in vitro. The type and amount of cytokine secretion depends on the type of co-cultivated oligosaccharide.

Keywords: Oligofructoside, Glycosyltransferase, Suc1, Aspergillus niger, SacB, Bacillus megaterium, CXCL8 (IL-8), CCL2 (MCP-1), Caco-2

\section{Background}

Inflammation processes are essential for the immune system of a host organism attacked by bacteria, viruses or other immunogenic molecules. However, persistent inflammation is a pathologic indication. The intestine, being the largest barrier of the human body to the environment, is under a state of persistent controlled inflammation because of its permanent contact with the gut microbiota. Intestinal epithelial cells release cytokines and chemokines upon external stimulation, e.g. by bacteria and their surface structures [1]. The factors which trigger inflammation and the release or suppression of cytokines and chemokines have been investigated thoroughly over the last decade, but the process is still not fully understood. Clearly, cytokine secretion can be triggered by lipopolysaccharide (LPS) on the surface of Gram-negative bacteria $[2,3]$ or capsular polysaccharides and lipoteichoic acid from Gram-positive species [4,5].

\footnotetext{
* Correspondence: seibel@chemie.uni-wuerzburg.de

${ }^{1}$ Department of Organic Chemistry, University of Wuerzburg, Am Hubland,

97074 Wuerzburg, Germany

Full list of author information is available at the end of the article
}

Oligo- and polysaccharides containing fructose have been known for several years as prebiotics [6,7]. Fructose recently was described as a signaling molecule and lead structure for carbohydrates with enhanced antigenicity in HIV vaccination [8]. The extent of the fructan oligoand polymerization was described as controllable in an enzymatic synthesis process [9]. Fructosyltransferases like inulosucrases and levansucrases which synthesize fructans of various chain lengths are common in many different bacteria including the gut microbiota [10]. The challenges to access large, branched oligosaccharides using chemical synthesis, may be overcome using chemo-enzymatic approaches [11-13]. Sucrose analogues synthesized by $\mathrm{SacB}$ from B. megaterium were used as precursors for the synthesis of oligofructosides with the fructosyltransferase Suc1 from A. niger [14]. For the present study, the enzymatic synthesis process was scaled up to yield biological test amounts. The tailored oligofructosides tested in this study are capped by the monosaccharides D-glucose, D-mannose, D-galactose, D-fucose or D-xylose, elongated with fructosyl units under tight control of the degree of polymerization. 
These oligofructosides are supposed to mimic the structural characteristics of immunogenic carbohydrate patterns of antigens, thus triggering the release of cytokines and/or chemokines.

\section{Results}

Chemo-enzymatic synthesis of novel oligofructosides by substrate engineering of fructosyltransferases

Tailored oligofructosides were synthesized, purified and characterized regarding their composition and stereochemistry. Substrate engineering of two fructosyltransferases from GRAS organisms (SacB from B. megaterium and Suc1 from $A$. niger) leads to novel tailor-made oligofructosides of defined fructosyl backbone lengths (Figures 1 and 2). The first step in their enzymatic synthesis is the formation of the $\alpha-(1,2)$ linked disaccharide (sucrose analogue). The fructosyltransferase SacB from B. megaterium provides access to the efficient synthesis of sucrose analogues (Gal-Fru, Man-Fru, XylFru and Fuc-Fru) under appropriate reaction conditions. The synthesis reaction was performed according to the process of sucrose analogue synthesis by SacB from $B$. subtilis [15]. However, SacB from B. megaterium proved to be much more efficient in terms of chemo-enzymatic synthesis with an increased substrate affinity $\left(K_{m} 6.6\right.$ compared to 14) and turnover number ( $\mathrm{k}_{\mathrm{cat}} 2200$ as opposed to 165) [16].

Each chemo-enzymatic synthesis process was analyzed by HPAEC. As an example, the process for Fuc-Fru synthesis is shown in Figure 3A. The distinct addition of the second and third unit of the fructosyl backbone was performed by the fructosyltransferase Suc1 from $A$. niger. Suc1 is highly specific for the synthesis of defined tri- and tetrasaccharides, 1-kestose $\left(\right.$ Glc-Fru $\left._{2}\right)$ and 1nystose $\left(\mathrm{Glc}_{\mathrm{C}} \mathrm{Fru}_{3}\right)$ and their analogues depending on the reaction conditions. Trisaccharide kestose analogues are Gal-(Fru $)_{2}$, Man-(Fru $)_{2}$, Xyl-(Fru $)_{2}$, and Fuc-(Fru $)_{2}$. Tetrasaccharide nystose analogues containing three fructosyl moieties are Gal-(Fru) $)_{3}$, Man-(Fru $)_{3}$, Xyl-(Fru $)_{3}$ and Fuc-(Fru $)_{3}$ (Figure 2$)$. The previously described products [14] as well as the novel fucosyl-capped tri- and tetrasaccharides were identified and analyzed by TLC and HPAEC. Scale-up of the synthesis process yields pure oligofructosides in cell culture test amounts (mg-scale, Table 1). As an example, the synthesis process for Fuc$\mathrm{Fru}_{2}$ and $\mathrm{Fuc}-\mathrm{Fru}_{3}$ is shown in Figure 3B.

\section{Oligofructoside-stimulated Caco-2 cells differentially secrete CXCL8 and CCL2}

The novel synthesized oligofructosides were tested in terms of immunostimulating properties on human epithelial Caco- 2 cells. This cell line is a model for the absorption of pharmacological products in the intestinal region $[17,18]$. 25 cytokines and chemokines were analyzed in the growth medium during co-cultivation with the novel oligofructosides (Eotaxin, GM-CSF, IFN- $\alpha$, IFN- $\gamma$, IL-1RA, IL- $1 \beta$, IL-2, IL-2R, IL-4, IL-5, IL-6, IL-7, IL-8, IL-10, IL-12p40/p70, IL-13, IL-15, IL-17, IP-10, MCP-1, MIG, MIP- $1 \alpha$, MIP-1 $\beta$, RANTES and TNF- $\alpha$, 25-plex cytokine analysis kit, Biosource, Invitrogen). Caco-2 cells were grown for $48 \mathrm{~h}$ in 24-well dishes containing the oligofructosides to be investigated in a concentration of $25 \mu \mathrm{M}$. Five-fold repeats of the experiment for each carbohydrate (four-fold for $\mathrm{MF}_{2}$ ) ensured the reproducibility of the results. CXCL8 (also known as interleukin 8, IL-8) and CCL2 (monocyte chemoattractant protein, MCP-1) were the only cytokines/chemokines in the media supernatants which led to a significant signal detected by the luminex system. Both standard curve fits show a correlation of over 99\% (data not shown). The measured fluorescence intensities are in the linear part of the standard curve indicating the reliability of the data. The other 23 cytokines and chemokines analyzed showed no significant response under these conditions. CCL2 generally shows a higher signal-tobackground enhancement compared to the cultivation of Caco-2 cells without added carbohydrates. The CCL2 release is increased up to a concentration of $320 \mathrm{pg} \mathrm{ml}^{-1}$ (Man-Fru 3 , Figure 4C, D). The characteristics of a longer fructosyl backbone seem to enhance this effect. For the tetrasaccharides 1-nystose (250 $\left.\mathrm{pg} \mathrm{ml}^{-1}\right), \mathrm{Man}^{-\mathrm{Fru}_{3}}$ (320 $\left.\mathrm{pg} \mathrm{ml}^{-1}\right)$, Fuc-Fru $\left(310 \mathrm{pg} \mathrm{ml}^{-1}\right)$ and Xyl-Fru $\left(220 \mathrm{pg} \mathrm{ml}^{-}\right.$ ${ }^{1}$ ), the release of CCL2 is clearly triggered (Figure 4C, D). The stimulation of CXCL8 is also observable when the fucose-containing 1-nystose analogue Fuc-Fru 3 is added (35 $\mathrm{pg} \mathrm{ml}^{-1}$ ). Also in the case of CXCL8, longer fructosyl

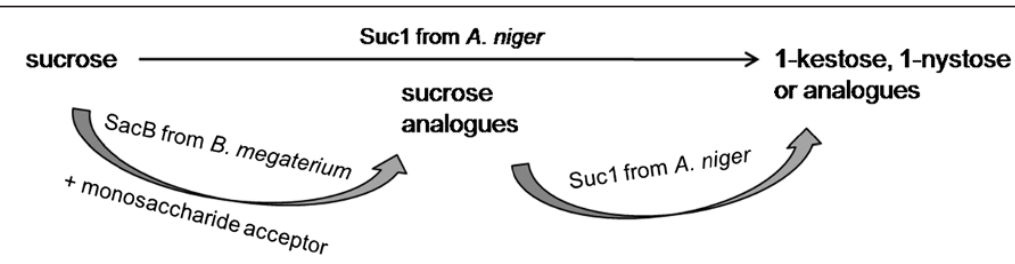

Figure 1 Enzymatic synthesis of novel oligofructosides. Oligofructosides used in this study were synthesized by the concerted action of two fructosyltransferases from B. megaterium (SacB) and A. niger (Suc1). 

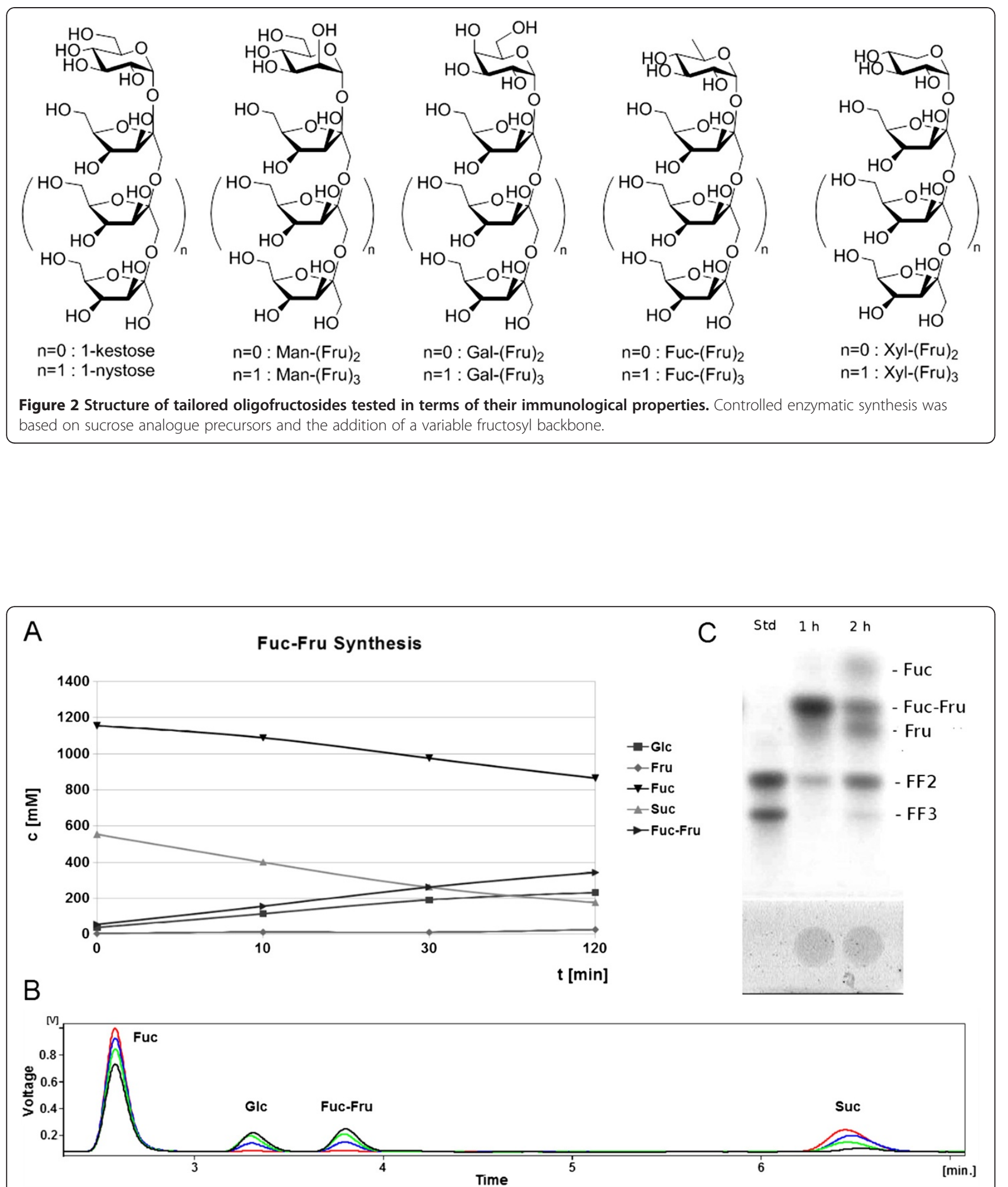

Figure 3 Synthesis of the oligofructosides capped by fucose. A, the acceptor reaction for the fucosyl-containing disaccharide Fuc-Fru was analyzed by HPAEC. Reaction conditions were: Fucose $(1.2 \mathrm{M})$, sucrose $(600 \mathrm{mM})$ in phosphate buffer after Sörensen $(50 \mathrm{mM}, \mathrm{pH} 6.6), 10 \mathrm{mg} \mathrm{I}^{-1}$ fructosyltransferase $\mathrm{SacB}$, at $200 \mathrm{rpm}$ and $37^{\circ} \mathrm{C}$ for $2 \mathrm{~h}$. B, the same acceptor reaction as in A shown as HPAEC chromatogram. Carbohydrates corresponding to the peaks are indicated. Analysis time points are indicated as follows. Red, 0 min, blue, 10min, green, 30 min and black, $2 \mathrm{~h}$ reaction time. $\mathbf{C}$, The transfructosylation reaction yielding the fucosyl-capped tri- and tetrasaccharides Fuc-(Fru $)_{2}$ and Fuc-(Fru $)_{3}$ was performed using Suc1-containing culture supernatant 1:50 (v/v), 500 mM Fuc-Fru in Sörensen`s phosphate buffer (50 mM, pH 5.6), at $45^{\circ} \mathrm{C}$ and $200 \mathrm{rpm}$. 
Table 1 Reaction times and yields for the oligosaccharide synthesis by the fructosyltransferase Suc1 from $A$. niger

\begin{tabular}{|c|c|c|}
\hline & $\frac{t}{[\min ]}$ & $\frac{\text { Conversion }}{\left[\% \mathrm{~mol} \mathrm{~mol}^{-1}\right]}$ \\
\hline 1-kestose & 18 & 81 \\
\hline 1-nystose & 60 & 93 \\
\hline $\mathrm{MF}_{2}$ & 60 & 71 \\
\hline $\mathrm{MF}_{3}$ & 180 & 87 \\
\hline $\mathrm{GF}_{2}$ & 420 & 44 \\
\hline $\mathrm{GF}_{3}$ & 960 & 65 \\
\hline$X F_{2}$ & 20 & 75 \\
\hline $\mathrm{XF}_{3}$ & 120 & 94 \\
\hline $\mathrm{FF}_{2}$ & 60 & 65 \\
\hline $\mathrm{FF}_{3}$ & 120 & 88 \\
\hline
\end{tabular}

Reaction conditions were Suc1 enzyme dilution 1:50 (v/v), $500 \mathrm{mM}$ sucrose analogue to be converted in Sörensen's phosphate buffer (50 mM, pH 5.6) at $45^{\circ} \mathrm{C}$ and $200 \mathrm{rpm}$. The reaction time depending on the oligosaccharide to be synthesized is indicated. chains seem to enhance the release of this cytokine. In the samples containing Man-Fru 3 (24 $\left.\mathrm{pg} \mathrm{ml}^{-1}\right), \mathrm{Fuc} \mathrm{Fru}_{3}$ (35 $\left.\mathrm{pg} \mathrm{ml}^{-1}\right)$ and Xyl-Fru $3\left(25 \mathrm{pg} \mathrm{ml}^{-1}\right)$ the highest concentrations of CXCL8 were detectable (Figure 4A, B). CXCL8 and CCL2 release was consistently not enhanced when incubated with the trisaccharides 1-kestose and Man-Fru (Figure 4).

\section{Discussion}

Co-incubation of human epithelial Caco-2 cells with certain types of pure, unconjugated oligofructosides leads to enhanced secretion of CXCL8 and CCL2. CXCL8 is a potent inflammation marker recruiting neutrophils to sites of infection. It is secreted by various cell types including epithelial cells [19]. CCL2 is described as an effective chemoattractor for monocytes from the blood stream [20]. Our results show that CCL2 release can be clearly triggered by the tetrasaccharide 1-nystose and

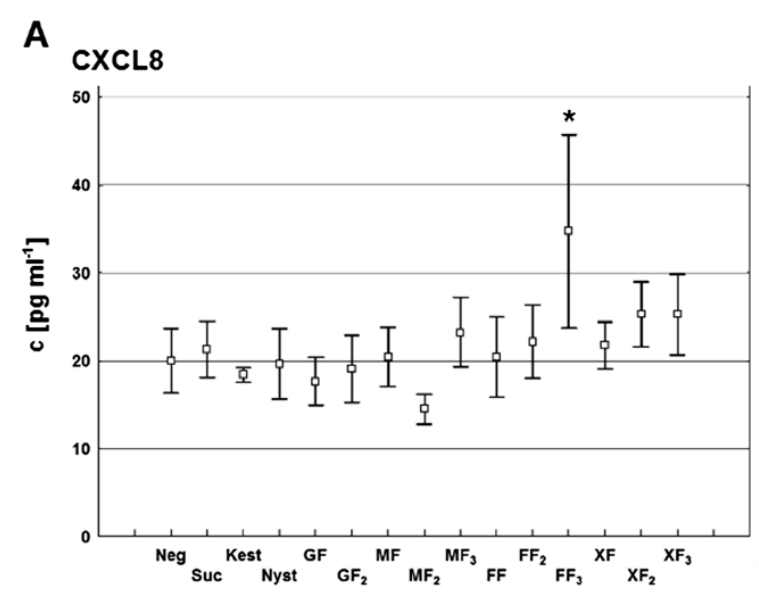

B

CXCL8

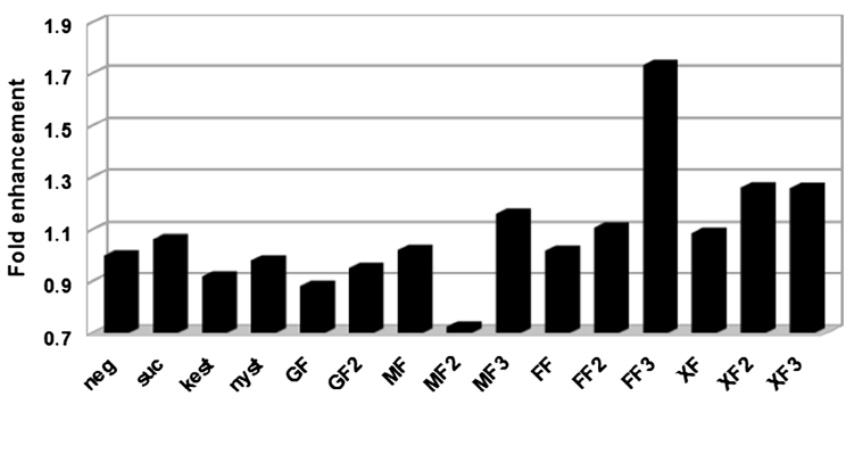

C $\mathrm{CCL} 2$

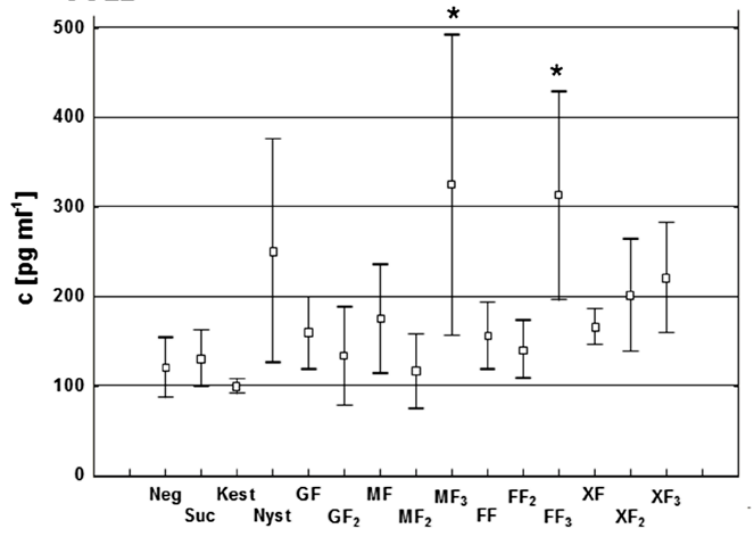

D CCL2

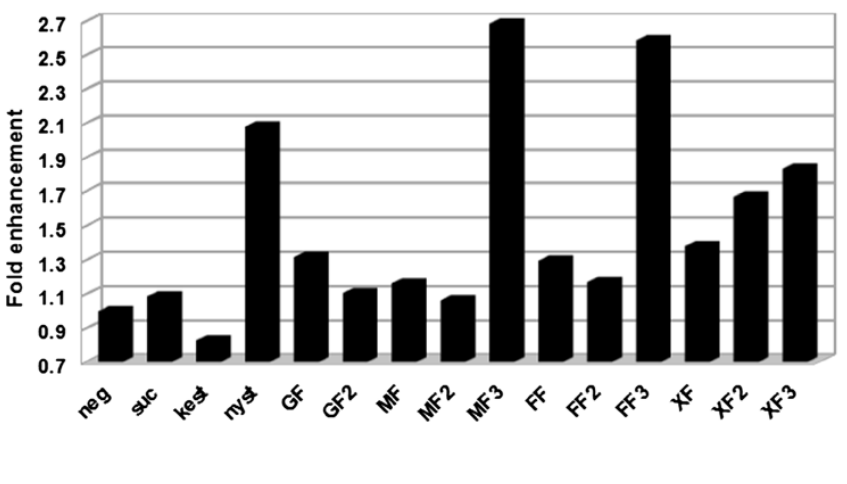

Figure 4 CXCL8 and CCL2 secretion level upon oligofructoside co-incubation of Caco-2 cells. A, C Secretion level of CXCL-8 (A) and CCL2 (C) after co-incubation with the oligofructoside indicated. B, D Means of $\mathbf{A}, \mathbf{C}$ were calculated as enhancement factors relative to cytokine/chemokine secretion level of the negative control. Significant differences according to the Fischer algorithm are indicated by a star. In $A_{1} F_{3}$ is significantly different from all other oligofructosides except for $\mathrm{XF}_{2}$ and $X F_{3}$. In $C_{1} \mathrm{FF}_{3}$ and $\mathrm{MF}_{3}$ differ significantly from $M F_{2}$ and kest. Caco-2 cells were incubated in the presence of $25 \mu \mathrm{M}$ oligofructoside at $37^{\circ} \mathrm{C}, 5 \% \mathrm{CO}_{2}$ for $48 \mathrm{~h}$. 
even more enhanced by the nystose analogues Man-Fru

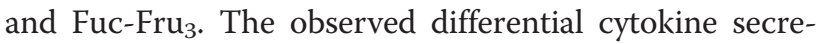
tion pattern raises questions: Is this stimulating effect dependent on the carbohydrate structure and if so, which structural elements trigger or suppress the release of cytokines and chemokines? Because of the differential secretion pattern and only two significant signals (out of 25 investigated), it was shown that cytokine secretion by Caco-2 cells in this assay is dependent on the oligofructoside type. But why are just 2 significant signals of secreted proteins detectable? One possibility is, that epithelial cells in the intestine only have a restricted repertoire of cytokines to be synthesized and secreted. Another point is, that this cell type is in constant contact with ubiquitous nutrients and commensal gut bacteria. Hence, it may have evolved tolerance against certain alien structures. The intestine being the largest barrier of the human body to the environment, has a special set of immunologically active cells. This area is under a state of persistent controlled inflammation because of its permanent contact with the gut microbiota. Special intestinal macrophages (IMACs) mediate tolerance to beneficial gut bacteria. Perturbations of these processes, like the release of CCL2, inhibit the differentiation of macrophages to IMACs thus leading to (chronic) inflammatory bowel diseases (IBDs) [21]. Intestinal epithelial cells release cytokines and chemokines upon external stimulation, e.g. by bacteria and their surface structures [1]. The factors which trigger inflammation and the release or suppression of cytokines and chemokines have been investigated thoroughly over the last decade, but the process is still not fully understood.

In this study, mannose- and fucose-capped oligofructosides generally evoke the highest increase in CCL2 and CXCL8 release (Figure 4). This might be due to their participation in natural cell-cell communication processes. Fucose often is a branching carbohydrate unit e.g. in the Lewis $\mathrm{X}$ motif. This motif is known as immunogenic under certain conditions, e.g. incomplete sialylation. Mannose is part of the core N-glycan structure. Its exposition often leads to the release of cytokines, e.g. CCL2 in mannosidase knock-out mice [22]. Interestingly, the different monosaccharide cap structure of the fructosyl backbone is not the only factor influencing the release of CXCL8 and CCL2, but also the length of the fructosyl backbone. For example, CCL2 secretion is triggered by 1-nystose and its tetrasaccharide analogues Man-Fru ${ }_{3}$ and $\mathrm{Fuc}_{-} \mathrm{Fru}_{3}$ but suppressed by kestose and its analogue $\mathrm{Man}_{-} \mathrm{Fru}_{2}$ (Figure 4). Thus, stereochemical and spatial aspects of oligosaccharides obviously have to be considered in terms of cell signalling processes. Recently, it was described that the different shape of bacterial lipopolysaccharide (LPS) determines which receptor is targeted and thus how cell signalling is processed [23-25]. The potential target receptors which are known to act competitively are shown in Additional file 1: Figure S1. The differential secretion of cytokines and thus the induction of an inflammatory response by the interaction of these receptors is still a scientific area with many long-standing questions.

\section{Conclusions}

Carbohydrates are ubiquitious structures on the surface of a plethora of different cell types including potentially pathogenic and beneficial gut bacteria. Auto-immune diseases like Crohn`s disease are linked to persistent, pathologic inflammation. As abundant surface structures of host and pathogen cells, carbohydrates may play an important role in the induction of inflammation and tolerance, respectively. Advances in carbohydrate research in combination with cell biology and immunology methods may lead to a detailed understanding of inflammation processes. The pure, tailored carbohydrate structures examined in this study induce such a differential secretion of cytokines in endothelial cells in vitro. Further advances in oligosaccharide synthesis lead broadened possibilities to investigate in vivo inflammation mechanisms of carbohydrate-cell receptor crosstalk. Controlled stimulation of the immune system may be one component towards a successful treatment of auto-immune diseases.

\section{Methods}

Chemo-enzymatic synthesis of tailored oligofructosides

The fructosyltransferases from the GRAS organisms $B$. megaterium (SacB) and A. niger (Suc1) were used for the synthesis of a fructosyl-based carbohydrate backbone capped with different types of monosaccharides (glucose, galactose, mannose, fucose and xylose).The oligofructosides were synthesized in two steps. First, sucrose analogues were synthesized by the fructosyltransferase $\mathrm{SacB}$ from B. megaterium. After analysis and purification, the elongation reaction was performed by the fructosyltransferase Suc1 from A. niger.

\section{Synthesis and purification of sucrose analogues by the fructosyltransferase SacB from bacillus megaterium}

For the synthesis of sucrose analogues, the acceptor monosaccharide was used in a concentration of $1.2 \mathrm{M}$. The transfructosylation reaction was performed with added sucrose $(600 \mathrm{mM})$ in phosphate buffer after Sörensen $(50 \mathrm{mM}, \mathrm{pH} 6.6)$. SacB was applied in a final concentration of $10 \mathrm{mg} \mathrm{l}^{-1}$ at $200 \mathrm{rpm}$ and $37^{\circ} \mathrm{C}$ for $2 \mathrm{~h}$ in a $1.5 \mathrm{ml}$ or $15 \mathrm{ml}$ reaction tube. The resulting sucrose analogues were analyzed qualitatively and quantitatively by thin-layer chromatography (TLC, 2.2) and high- 
performance anion exchange chromatography (HPAEC, 2.3). The purification of the sucrose analogues was performed by a silica column with a carbohydratecontaining mobile phase (60\% ethylacetate, $30 \%$ isopropanol, $10 \%$ water, all v/v). The products were analyzed by TLC and HPAEC.

\section{Synthesis and purification of 1-kestose, 1-nystose and analogues by the fructosyltransferase Suc1 from aspergillus Niger}

The subsequent synthesis step of 1-kestose, 1-nystose and their analogues was performed by the fructosyltransferase Suc1 from $A$. niger as described previously with the sucrose analogues synthesized by $\mathrm{SacB}$ from $B$. subtilis [14]. Briefly, the supernatant of a cultivation of $A$. niger SKAN1015 was used in a dilution of 1:50 (v/v). The Suc1 dilution was mixed with $500 \mathrm{mM}$ of the sucrose analogue to be converted in Sörensen's phosphate buffer $(50 \mathrm{mM}$, $\mathrm{pH}$ 5.6). The reaction was performed at $45^{\circ} \mathrm{C}$ and 200 $\mathrm{rpm}$. The reaction time depends on the desired oligofructoside to be synthesized [14].The purification of 1-kestose, 1-nystose and their analogues was performed by size exclusion chromatography. An open chromatography gel filtration system was used (Biogel, Bio-Rad) and degassed water containing the carbohydrates to be separated as mobile phase.

\section{Analysis of carbohydrates by thin-layer chromatography (TLC)}

The sample was diluted to a total carbohydrate concentration of $1-3 \mathrm{~g} \mathrm{l}^{-1} .3 \mu \mathrm{l}$ of the sample was applied on a TLC plate (TLC aluminium foil coated with silica 60 , $20 \times 20 \mathrm{~cm}$ with concentration zone, Merck). After drying the TLC was run in a TLC chamber equilibrated with the mobile phase. After $45 \mathrm{~min}$ the plate was dried and again incubated for $45 \mathrm{~min}$. The staining of the carbohydrates was performed by a short dive into the developing solution (sulfuric acid 5\% (v/v) $\mathrm{N}$-(1-naphtyl) ethylendiamine dihydrochloride $0.3 \%(\mathrm{w} / \mathrm{v})$ in methanol) and incubation at $150^{\circ} \mathrm{C}$ for $5 \mathrm{~min}$. An appropriate standard has to be applied each time (here: glucose $0.1 \mathrm{~g} \mathrm{l}^{-1}$, fructose $0.1 \mathrm{~g} \mathrm{l}^{-1}$, sucrose $0.1 \mathrm{~g} \mathrm{l}^{-1}, 1$ kestose $0.1 \mathrm{~g} \mathrm{l}^{-1}, 1$-nystose $0.1 \mathrm{~g} \mathrm{l}^{-1}$ ).

\section{Analysis of carbohydrates by high-performance anion exchange chromatography (HPAEC)}

HPAEC analysis was used to determine the kinetic parameters of the enzyme reactions and the optimal reaction conditions. The HPAEC is a modular high-performance liquid chromatography optimized for the analysis of carbohydrates. The pre-column (CarboPac PA1, 4*50 mm, Dionex) and the following seperation column (CarboPac PA1 4*250 mm, Dionex)) of the HPAEC device are used to separate the carbohydrates with a gradient of the
Table 2 HPAEC eluent gradient program

\begin{tabular}{lc}
\hline $0-5 \mathrm{~min}$ & $0 \% 1 \mathrm{M} \mathrm{NaAc}$ \\
\hline $5-25 \mathrm{~min}$ & to $25 \% 1 \mathrm{M} \mathrm{NaAc}$ \\
\hline $25-30 \mathrm{~min}$ & to $50 \% 1 \mathrm{M} \mathrm{NaAc}$ \\
\hline $30-35 \mathrm{~min}$ & $50 \% 1 \mathrm{M} \mathrm{NaAc}$ \\
\hline $35-37 \mathrm{~min}$ & to $0 \% 1 \mathrm{M} \mathrm{NaAc}$ \\
\hline $37-60 \mathrm{~min}$ & $0 \% 1 \mathrm{M} \mathrm{NaAc}$ \\
\hline
\end{tabular}

eluent ( $1 \mathrm{M}$ sodium acetate in $0.1 \mathrm{M}$ sodium hydroxide in MilliQ, Millipore, deionized water, protocol see Table 2). The samples were applied by an autosampler (Perkin Elmer). A degaser unit was used for removing oxygen and carbon dioxide from the mobile phase (sodium hydroxide, $100 \mathrm{mM}$ in water) and the eluent (sodium hydroxide, $100 \mathrm{mM}$ and sodium acetate, $1 \mathrm{M}$ in water). A thermostat ensured a stable temperature of

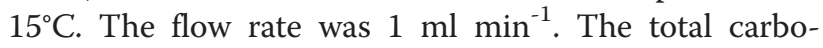
hydrate concentration has to be set to $100-200 \mathrm{mg}$ $\mathrm{I}^{-1}$ correlating with the used detector sensitivity of " $1 \mathrm{k}$ ". The chromatograms were recorded with the software Clarity (Ver. 2.4.1.77, DataApex).

\section{Co-cultivation of Caco-2 cells with tailor-made oligofructosides}

Caco-2 cells were cultivated in Dulbecco's modified Eagle`s medium (DMEM)/HamsF12 (Gibco) supplied with $10 \%$ fetal calf serum (FCS) and $200 \mu \mathrm{g}^{-1}$ ampicillin at $37^{\circ} \mathrm{C}$ and $5 \% \mathrm{CO}_{2}$. At $80 \%$ confluency, cells were split in a ratio of $1: 10$. For the oligofructoside assay, Caco-2 cells at $80 \%$ confluence were cultivated in 24-well dishes (Gibco). The split ratio was 1:10 and each well was supplied with the carbohydrate to be tested in a concentration of $25 \mu \mathrm{M}$. After $48 \mathrm{~h}$, from each well a sample of the media supernatant was collected for cytokine analysis.

\section{Cytokine and chemokine detection assay}

For the oligofructoside assay, Caco- 2 cells at $80 \%$ confluence were split as described and cultivated in 24-well dishes (Biochrom). Each well was supplied with the oligofructoside to be tested (final concentration $25 \mu \mathrm{M}$ ). After $48 \mathrm{~h}$ (80\% confluence) the supernatant medium was collected for cytokine analysis. The assay was performed with a 25-plex human cytokine analysis kit according to the manufacturer's instructions (Biosource, Invitrogen). Briefly, the supernatant medium was incubated with antibody-functionalized beads and detected with biotinylated secondary antibodies. Streptavidin-Rphycoerythrin was used as fluorescence marker. The final analysis was performed by the luminex system which recognizes spectral properties of the beads and quantifies the bead load by the specific fluorescence 
intensity. 25 cytokines were analyzed in parallel per sample (Eotaxin, GM-CSF, IFN- $\alpha$, IFN- $\gamma$, IL-1RA, IL- $1 \beta$, IL2, IL-2R, IL-4, IL-5, IL-6, IL-7, IL-8, IL-10, IL-12p40/ p70, IL-13, IL-15, IL-17, IP-10, MCP-1, MIG, MIP-1 $\alpha$, MIP- $1 \beta$, RANTES, TNF- $\alpha$ ) according to the manufacturer`s instructions (luminex system, Qiagen).

\section{Additional file}

Additional file 1: Figure S1. Lipopolysaccharide interactions with cell surface-located Toll-like receptors 2 and 4 . The different shapes of bacterial lipopolysaccharides (LPS) are keys for the identification of their target receptor (simplified adaption from [17]). Here, the shape of LPS ligands is determined by the grade of fatty acid substitution. The distinct receptor binding mode depending on the molecular conformation is supposed to be mimicked by the oligosaccharides tested in this study.

\section{Abbreviations}

Gal-Fru: GF, a-D-galactopyranosyl-(1,2)- $\beta$-D-fructofuranoside; Man-Fru: MF, aD-mannopyranosyl-(1,2)- $\beta$-D-fructofuranoside; Xyl-Fru: XF, a-D-xylopyranosyl(1,2)- $\beta$-D-fructofuranoside; Fuc-Fru: FF, a-D-fucopyranosyl-(1,2)- $\beta$-Dfructofuranoside.

\section{Competing interests}

The authors declare no competing interests.

\section{Authors' contributions}

$\mathrm{AH}$ and MT performed experiments. $\mathrm{AH}$ and JS designed the experiments and analysed the data. AH and JS wrote the manuscript. All authors read and approved the manuscript.

\section{Acknowledgments}

This work was performed within the Collaborative Research Centre (SFB) 578 supported by the German Research Foundation (DFG). The authors gratefully acknowledge excellent support with the luminex analysis system by Bastian Pasche (Helmholtz-Centre for Infection Research, Germany).

This publication was funded by the German Research Foundation (DFG) and the University of Wuerzburg in the funding programme Open Access Publishing.

\section{Author details}

${ }^{1}$ Department of Organic Chemistry, University of Wuerzburg, Am Hubland, 97074 Wuerzburg, Germany. ${ }^{2}$ Present address: Research Center Borstel, Parkallee 1-40, 23845, Borstel, Germany.

Received: 15 June 2012 Accepted: 16 November 2012 Published: 26 November 2012

\section{References}

1. Sonier B, Patrick C, Ajjikuttira P, Scott FW: Intestinal immune regulation as a potential diet-modifiable feature of gut inflammation and autoimmunity. Int Rev Immunol 2009, 28:414-445.

2. Ulevitch RJ, Tobias PS: Receptor-dependent mechanisms of cell stimulation by bacterial endotoxin. Annu Rev Immunol 1995, 13:437-457.

3. Stevens DL: Superantigens: their role in infectious diseases. Immunol Invest 1997, 26:275-281.

4. Standiford TJ, Arenberg DA, Danforth JM, Kunkel SL, VanOtteren GM, Strieter RM: Lipoteichoic acid induces secretion of interleukin-8 from human blood monocytes: a cellular and molecular analysis. Infect Immun 1994, 62:119-125.

5. Soell M, Diab M, Haan-Archipoff G, Beretz A, Herbelin C, Poutrel B, Klein JP: Capsular polysaccharide types 5 and 8 of staphylococcus aureus bind specifically to human epithelial (KB) cells, endothelial cells, and monocytes and induce release of cytokines. Infect Immun 1995, 63:1380-1386.

6. Yun JW: Fructooligosaccharides-occurrence, preparation, and application. Enzyme Microb Technol 1996, 19:107-117.
7. Gibson GR: Dietary modulation of the human gut microflora using the prebiotics oligofructose and inulin. J Nutr 1999, 129:1438S-1441S.

8. Doores KJ, Fulton Z, Hong V, Patel MK, Scanlan CN, Wormald MR, Finn MG, Burton DR, Wilson IA, Davis BG: A nonself sugar mimic of the HIV glycan shield shows enhanced antigenicity. Proc Natl Acad Sci USA 2010, 107:17107-17112

9. Strube CP, Homann A, Gamer M, Jahn D, Seibel J, Heinz DW: Polysaccharide synthesis of the levansucrase SacB from bacillus megaterium is controlled by distinct surface motifs. J Biol Chem 2011, 286:17593-17600

10. Lammens W, Le Roy K, Schroeven L, Van Laere A, Rabijns A, Van den Ende W: Structural insights into glycoside hydrolase family 32 and 68 enzymes: functional implications. J Exp Bot 2009, 60:727-740.

11. Bernardes GJL, Castagner B, Seeberger PH: Combined approaches to the synthesis and study of glycoproteins. ACS Chem Biol 2009, 4:703-713.

12. Seeberger PH, Werz DB: Synthesis and medical applications of oligosaccharides. Nature 2007, 446:1046-1051.

13. Boltje TJ, Buskas T, Boons G-J: Opportunities and challenges in synthetic oligosaccharide and glycoconjugate research. Nat Chem 2009, 1:611-622.

14. Zuccaro A, Götze S, Kneip S, Dersch P, Seibel J: Tailor-made fructooligosaccharides by a combination of substrate and genetic engineering. ChemBioChem 2008, 9:143-149.

15. Seibel J, Moraru R, Götze S, Buchholz K, Na'amnieh S, Pawlowski A, Hecht $\mathrm{H}-\mathrm{J}$ : Synthesis of sucrose analogues and the mechanism of action of bacillus subtilis fructosyltransferase (levansucrase). Carbohydr Res 2006, 341:2335-2349.

16. Homann A, Biedendieck R, Götze S, Jahn D, Seibel J: Insights into polymer versus oligosaccharide synthesis: mutagenesis and mechanistic studies of a novel levansucrase from bacillus megaterium. Biochem J 2007, 407:189-198.

17. Artursson P, Palm K, Luthman K: Caco-2 monolayers in experimental and theoretical predictions of drug transport. Adv Drug Deliv Rev 2001, 46:27-43

18. Shah P, Jogani V, Bagchi T, Misra A: Role of Caco-2 cell monolayers in prediction of intestinal drug absorption. Biotechnol Prog 2006, 22:186-198.

19. Rollins BJ: Chemokines. Blood 1997, 90:909-928.

20. Carr MW, Roth SJ, Luther E, Rose SS, Springer TA: Monocyte chemoattractant protein 1 acts as a T-lymphocyte chemoattractant. Proc Natl Acad Sci USA 1994, 91:3652-3656.

21. Spoettl T, Hausmann M, Herlyn M, Gunckel M, Dirmeier A, Falk W, Herfarth $\mathrm{H}$, Schoelmerich J, Rogler G: Monocyte chemoattractant protein-1 (MCP-1) inhibits the intestinal-like differentiation of monocytes. Clin Exp Immunol 2006, 145:190-199.

22. Green RS, Stone EL, Tenno M, Lehtonen E, Farquhar MG, Marth JD: Mammalian $\mathrm{N}$-glycan branching protects against innate immune selfrecognition and inflammation in autoimmune disease pathogenesis. Immunity 2007, 27:308-320.

23. Netea MG, van Deuren M, Kullberg BJ, Cavaillon J-M, Van der Meer JWM: Does the shape of lipid a determine the interaction of LPS with toll-like receptors? Trends Immunol 2002, 23:135-139.

24. Furrie $\mathrm{E}$, Macfarlane $\mathrm{S}$, Thomson G, Macfarlane GT: Toll-like receptors-2, -3 and -4 expression patterns on human colon and their regulation by mucosal-associated bacteria. Immunology 2005, 115:565-574.

25. Harn DA, McDonald J, Atochina O, Da'dara AA: Modulation of host immune responses by helminth glycans. Immunol Rev 2009, 230:247-257.

doi:10.1186/1472-6750-12-90

Cite this article as: Homann et al:: Chemo-enzymatic synthesis and in vitro cytokine profiling of tailor-made oligofructosides. BMC Biotechnology 2012 12:90. 